\title{
The Prevalence and Infection's Degree of Gastrointestinal Worm of Local Chicken (Gallus Domesticus) in Kramat Village, District of Bangkalan, Madura, East Java Indonesia \\ Prevalensi dan Derajat Infeksi Cacing Saluran Pencernaan pada Ayam Buras (Gallus Domesticus) di Desa Kramat Kecamatan Bangkalan Kabupaten Bangkalan
}

\author{
${ }^{1)}$ Ellza Agatha Damayanti, ${ }^{2)}$ Poedji Hastutiek, ${ }^{3)}$ A.T. Soelih Estoepangestie, ${ }^{2)}$ Nunuk Dyah \\ Retno L, ${ }^{2)}$ Kusnoto, ${ }^{2)}$ Endang Suprihati \\ ${ }^{1)}$ Student, Faculty of Veterinary Medicine, Universitas Airlangga \\ ${ }^{2}$ Department of Veterinary Parasitology, Faculty of Veterinary Medicine, Universitas Airlangga \\ ${ }^{3)}$ Departement of Veterinary Public Health, Faculty of Veterinary Medicine, Universitas Airlangga \\ Received: 25-02-2019, Accepted: 10-03-2019, Published Online: 19-03-2019
}

\begin{abstract}
The study was aimed to know the prevalence and level of gastrointestinal worm investation of local chicken (Gallus domesticus) in Kramat Village, district of Bangkalan, Madura East Java province. The samples used in the study were 100 faeces of kampung chicken. using sedimentation and floating method. Faeces samples were tested, than followed by microscopically test to identify the worm is species. The result showed that in 38 out of 100 samples could be indentified some worm species as followed : Capillaria sp.14 $(36,8 \%)$, Railletina 7 (18,4\%), Hymenolepis $16(42,1 \%)$ and Heterakis gallinarum $1(2,6 \%)$. Using Mann Whitney U-test could be differentiated the level of the infection with an average of 45.53 in cock, while in hen with an average of 55.47. There was no significancy $(\mathrm{p}>0,05)$ on the level of worm gastrointestinal infection of different sex of kampung chicken.
\end{abstract}

Keywords: kampung chicken, male and female sex, gastrointestinal worms, prevalence, degree of infection.

\section{Pendahuluan}

Ayam buras merupakan sumber plasma nuftah hewani yang sangat berharga, tetapi belum tergali potensinya secara optimal. Penyebarannya sangat luas, merata diseluruh pelosok tanah air. Daya adaptasinya dengan lingkungan setempat tidak diragukan lagi, ketahanan penyakitnya lebih baik dibandingkan dengan ayam ras. Keberadaannya ditengah masyarakat telah menjadi bagian kehidupan masyarakat pedesaan maupun perkotaan, dan potensinya dikembangkan sebagai ternak produksi (Sulistyati dkk., 2001).

Parasit helminth atau cacing secara alami ditemukan pada berbagai jenis unggas liar dan unggas peliharaan. Parasit yang sering menginfeksi unggas peliharaan seperti bebek, itik, burung dan ayam adalah Nematoda (Cynthia, 2009). Helminthiosis pada ayam buras yang terjadi karena infeksi alami pada umumnya merupakan infeksi campuran dari Trematoda (cacing daun), Cestoda (cacing pita), dan Nematoda (cacing gilig). Berbagai faktor yang mempengaruhi pola infeksi tersebut adalah populasi cacing stadium infektif di dalam inang antara, dan pola penyebarannya, kekhasan inang habitat serta pola makannya (Lawson and Gemmel, 1983).Sedangkan kelangsungan hidup cacing stadium infektif di alam sangat ditentukan oleh interaksi antara kondisi alam yaitu suhu, kelembaban, dan curah hujan yang setiap jenis cacing mempunyai tingkat ketahanan yang berbeda (Ridwan et al., 1996), terutama pada periode perkembangan yang sangat sensitif di dalam telur maupun tubuh inang antara.

Keberadaan parasit di dalam tubuh ayam buras dapat menyebabkan kerusakan organorgan tertentu. Ayam yang terserang penyakit ini akan mengalami penurunan berat badan dan penurunan produksi telur, ehingga ayam menjadi lemah dan kurus bahkan menyebabkan kematian (Levine, 1995).

Berdasarkan beberapa penelitian helminthiasis pada ayam kampung pada kurun waktu antara 1973-1995 di Indonesia menunjukkan 
angka kejadian yang masih relatif tinggi (Siahaan, 1993; Inbandiah, 1995).

Penyebaran parasit terhadap hewan ternak dapat melalui pakan, air, peralatan ternak dan sistem pemeliharaan ternak (Parede et al. 2005). Hal ini pertanda bahwa tindakan pengendalian yang efektif belum dilakukan yaitu dengan tindakan kombinasi antara pengobatan dengan anthelmintik dan perbaikan manajemen peternakan (Fabiyi and Nansen, 1986) yang didasari oleh pengetahuan fluktuasi populasi cacing serta faktor-faktor transmisinya (Roberts, 1994). Berdsarkan survei yang dilakukan di Desa Kramat Kecamatan Bangkalan Kabupaten Bangkalan diperoleh informasi bahwa pernah terjadi kematian pada ayam buras yang masih belum diketahui penyebabnya. Ayam buras di desa tersebut dipelihara secara ekstensif dan intensif.

\section{Materi Dan Metode Penelitian Tempat dan Waktu Penelitian}

Pengambilan sampel berupa 100 feses ayam buras di Desa Kramat Kecamatan Bangkalan Kabupaten Bangkalan. Penelitian ini dilaksanakan di Departemen Parasitologi Fakultas Kedokteran Hewan Universitas Airlangga. Penelitian ini berlangsung pada bulan Mei-Juni 2018.

\section{Alat dan Bahan Penelitian}

Bahan utama yang digunakan dalam penelitian ini adalah feses ayam yang diambil dari saluran pencernaan ayam dan diawetkan dengan menggunakan formalin $10 \%$, aquadest dan larutan gula jenuh.

Alat yang digunakan dalam penelitian ini adalah sendok plastik, kantung plastik, mikroskop, gelas, pipet, gelas pengaduk, saringan, mortir, tabung centrifuge, centrifuge, objek glass, cover glass, kertas label dan opti lab.

\section{Metode Penelitian}

Sampel yang digunakan dalam penelitian ini adalah feses ayam buras yang diperoleh dari Desa Kramat Kecamatan Bangkalan Kabupaten Bangkalan. Pengambilan sampel dimulai dari bulan Mei sampai bulan Juli. Setelah feses sudah mencukupi jumlah yang ditentukan yaitu 100 sampel lalu dibawa ke Departemen Parasitologi Universitas Airlangga Surabaya untuk dilakukan pemeriksaan.

Sampel feses diambil dari saluran pencernaan ayam lalu dimasukkan kedalam plastik yang diberi Formalin $10 \%$ sebagai pengawet. Setiap plastik diberi label atau penanda nomor sampel. Lalu di sesuaikan dengan pendataan sampel.

Pemeriksaan sampel feses dilakukan dengan metode sederhana (natif), sedimen dan pengapungan. Hasil pemeriksaan dinyatakan positif bila ditemukan adanya telur cacing pada pengamatan dibawah mikroskop.

\section{Analisis Data}

Data yang diperoleh dianalisis menggunakan Chi Square Testdan Mann Whitney U-Test dalam program padaStatistical Product and Service Solution (SPSS) versi 21. untuk mengetahui adanya perbedaan prevalensi dan derajat infeksi cacing saluran pencernaan ayam buras di Desa Kramat Kecamatan Bangkalan Kabupaten Bangkalan. Prevalensi dihitung berdasarjab sampel + / total sampel dinyatakan dalam \%.

\section{Hasil dan Pembahasan}

Jenis Cacing Saluran Pencernaan pada Ayam Buras di Desa Kramat Kecamatan Bangkalan Kabupaten Bangkalan

Berdasarkan hasil pemeriksaan terhadap 100 sampel feses ayam buras dengan menggunakan metode sedimentasi dan apung diperoleh hasil bahwa 38 ekor ayam buras dinyatakan positif terinfeksi satu jenis cacing saluran pencernaan yaitu Capillaria sp., Railletina sp., Hymenolepis dan Heterakis gallinarum. Hasil tersebut dapat dilihat pada Tabel 1.

Tabel 1. Telur Cacing Saluran Pencernaan pada Ayam Buras di Desa Kramat Kecamatan Bangkalan Kabupaten Bangkalan

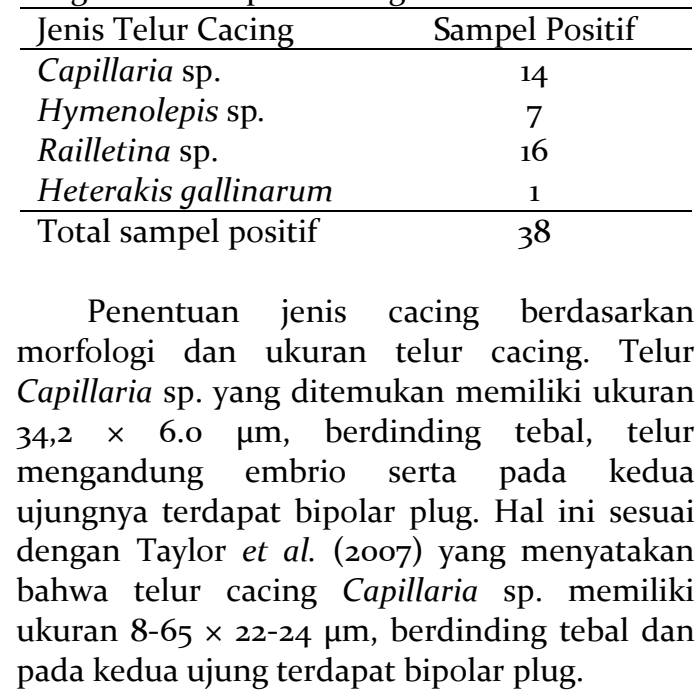




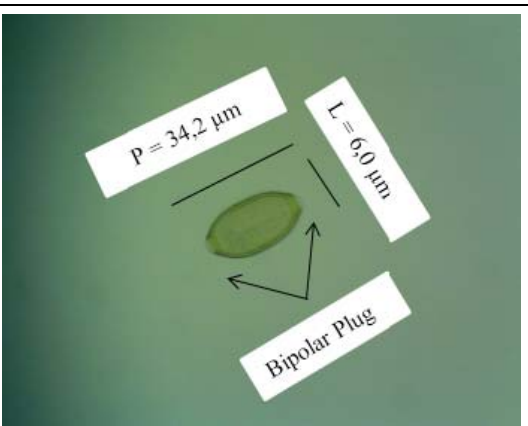

Gambar 1. Telur Capillaria sp. Perbesaran 1oox

Telur Railletina sp. yang ditemukan memiliki ukuran 26,7 × 23,6 $\mu \mathrm{m}$, memiliki dinding tebal berbentuk bulat. Hal ini sesuai dengan Solusby (1986) menyatakan bahwa telur cacing Railletina sp. memiliki diameter 25-50 $\mu \mathrm{m}$. Telur berbentuk bulat dan di dalamnya terdapat bentukan hexacanth embrio, cacing Railletina sp. memiliki panjang badan mencapai $25 \mathrm{~cm}$. Soulsby (1986) juga menyatakan bahwa telur cacing Hymenolepis sp. memiliki ukuran 30-55 $\times$ 44-62 $\mu \mathrm{m}$, berbentuk bulat dan di dalam telur terdapat bentukan hexacanth embrio, cacing Hymenolepis sp. memiliki panjang badan 25-40 mm. Berdasarkan kunci identifikasi dari Soulsby (1986) telur cacing cestoda yang ditemukan pada penelitian ini kemungkinan telur Railletina $s p$. atau telur Hymenolepis sp. perlu dilakukan penelitian lebih lanjut dengan melihat morfologi dan ukuran cacing saluran pencernaan untuk menentukan jenis cacing cestoda yang menginfeksi ayam buras di Desa Kramat Kecamatan Bangkalan Kabupaten Bangkalan.

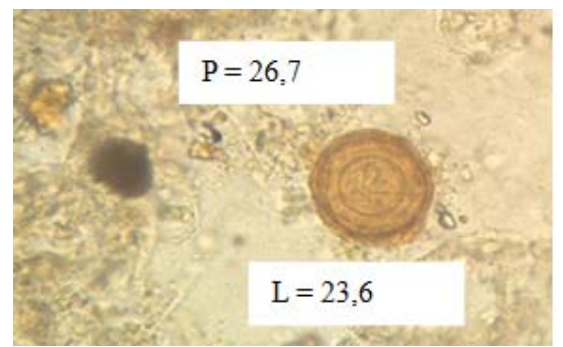

Gambar 2. Telur Railletina sp. perbesaran 40ox

Telur cacing Heterakis gallinarum yang ditemukan memiliki ukuran $26,7 \times 23,6 \mu \mathrm{m}$, telurnya berbentuk elips dan berdinding tebal. Berdasarkan hasil identifikasi morfologi diperoleh bahwa larva cacing spesies ini berbentuk slinder dan panjang serta berkelok. Hal ini sesuai dengan pendapat Iresh dan Subronto (2015) yang menyatakan bahwa morfologi Heterakis gallinarum berbentuk slinder, panjang, berkelok, diameter dari pangkal sampai ujung ekor semakin mengecil dan panjang larva dapat mencapai $2 \mathrm{~cm}$.

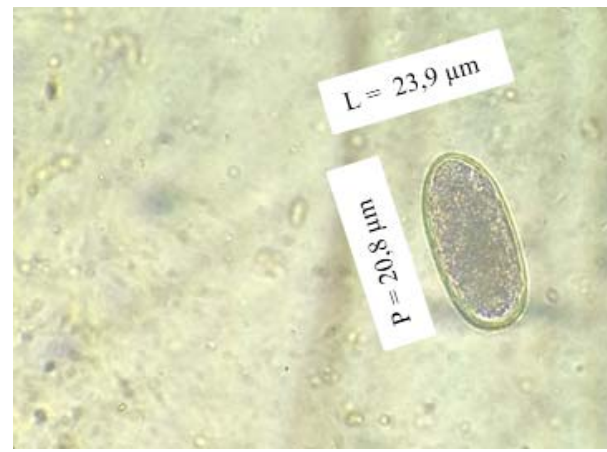

Gambar 3. Telur Heterakis gallinarum perbesaran $400 x$

Prevalensi Cacing Saluran Pencernaan pada Ayam Buras di Desa Kramat Kecamatan Bangkalan Kabupaten Bangkalan

Berdasarkan hasil pemeriksaan 100 sampel feses ayam buras antara jantan dan betina diperoleh hasil sebanyak 23 sampel positif, sedangkan 15 sampel positif feses ayam buras betina yang dapat dilihat pada Tabel 2.

Tabel 2. Prevalensi cacing saluran pencernaan pada ayam buras di Desa Kramat Kecamatan Kabupaten Bangkalan

\begin{tabular}{lccc}
\hline Jenis Kelamin & Positif & Negatif & Total \\
\hline Jantan & 15 & 35 & 50 \\
Betina & 23 & 27 & 50 \\
\hline
\end{tabular}

Analisis Chi Square dari jenis kelamin tersebut terhadap prevalensi cacing saluran pencernaan ayam buras menunjukkan hasil yang tidak signifikan. Hal ini berarti bahwa prevalensi cacing saluran pencernaan tidak dipengaruhi oleh jenis kelamin, sehingga ayam buras jantan maupun betina mempunyai proporsi yang sama.

Derajat Infeksi Cacing Saluran Pencernaan pada Ayam Buras di Desa Kramat Kecamatan Bangkalan Kabupaten Bangkalan

Pada perhitungan dengan metode TCPGT didapatkan nilai rata-rata pada ayam buras jantan sebesar 45.53 sedangkan pada ayam buras betina didapatkan nilai rata-rata sebesar 55.47 di Desa Kramat Kecamatan Bangkalan Kabupaten Bangkalan. Hasil tersebut dapat dilihat pada Tabel 3 . 
Tabel 3. Rata-rata Perhitungan TCPGT pada Sampel Feses Ayam Buras di Desa Kramat Kecamatan Bangkalan Kabupaten Bangkalan

\begin{tabular}{lcc}
\hline Jenis Kelamin & Positif & Mean Rank \\
\hline Jantan & 15 & 45.33 \\
Betina & 27 & 55.57 \\
\hline
\end{tabular}

Hasil Mann Whitney U Test dari kedua jenis kelamin tersebut terhadap derajat infeksi cacing saluran pencernaan ayam buras menunjukkan hasil yang tidak signifikan (p>0,05), hal ini berarti bahwa derajat infeksi cacing saluran pencernaan tidak dipengaruhi oleh jenis kelamin ayam buras tersebut, sehingga baik jantan maupun betina mempunyai proporsi yang sama.

Proses perkembangan, ketahanan hidup dan penyebaran telur atau larva cacing yang infektif di dalam inang antara yang dikenal dengan istilah translasi dipengaruhi oleh lingkungan dimana cacing itu berada, terutama perubahan musim atau cuaca dan manajemen peternakan (Armour, 1980).

Penelitian ini sesuai dengan yang pernah dilakukan oleh Pradana dkk (2015) yang menyatakan bahwa presentase Ascaridia galli sebesar $60 \%$ dan Strongyloides sp sebesar $28 \%$ pada ayam buras. Tingginya tingkat prevalensi tersebut karena cacing ini dapat bertahan di tempat yang lembab. Faktor cuaca seperti temperatur dan kelembaban yang sesuai dengan kehidupan cacing serta manajemen atau cara pemeliharaan dan pemberian pakan yang kurang baik dapat mendukung terjadinya infeksi cacingan. Penelitian tersebut menunjukkan hasil yang sangat signifikan antara daerah dataran tinggi dengan dataran rendah terhadap prevalensi dan derajat infeksi cacing saluran pencernaan pada ayam buras, hasil tersebut juga menunjukkan bahwa dataran tinggi memiliki proporsi yang lebih besar terhadap prevalensi dan derajat infeksi cacing saluran pencernaan karena tingkat kelembabannya yang cukup tinggi (Yulianto, 2007).

Hasil dari perhitungan Telur Cacing Per Gram Tinja (TCPGT) di kedua jenis kelamin tersebut menunjukkan derajat infeksi cacing saluran pencernaan pada ayam buras tergolong infeksi sedang, hal ini dimungkinkan karena ternak ayam buras kurang tahan terhadap penyakit (Suprianiandono dkk., 2011).

Pada identifikasi jenis cacing saluran pencernaan di kedua jenis kelamin tersebut ditemukan empat jenis cacing yaitu Capillaria sp.,Hymenolepis sp., Railletina sp. dan Heterakis
Gallinarum. Hasil ini sedikit berbeda dengan penelitian yang dilakukan Retnani (2009) tiga genera cestoda telah dilaporkan menginfeksi ayam ras petelur di Pulau Jawa, yaitu di daerah Bogor Jawa Barat: Railletina, Choanotaenia dan Hymenolepis. Infeksi Railletina di Asia juga sangat tinggi $(84,2 \%)$, sedangkan Choanotaenia hanya (7\%) dan Hymenolepis hanya (6\%) (Permin dan Hansen 1998). Demikian pula di Mesir dilaporkan insidensi tertinggi cestodosis adalah pada genus Railletina (Shahin et al. 2011). Pada penelitian ini hanya ditemukan empat jenis cacing tersebut dimungkinkan karena metode pemeriksaan yang digunakan yaitu pemeriksaan feses menggunakan metode sedimentasi dan apung sedangkan metode pemeriksaan yang digunakan oleh Retnani (2009) yaitu metode nekropsi.

Cacing Railletina sp. merupakan jenis cacing yang paling banyak ditemukan di Desa Kramat, hal ini dimungkinkan berkaitan dengan siklus hidup tidak langsung Cestoda akan termakan inang antara yang sesuai tetapi memerlukan waktu yang lama, tergantung kondisi alam (Kusumamihardja, 1990). Pada siklus hidupnya Cestoda memerlukan inang antara berupa kumbang tinja, kumbang tanah, kumbang hitam, semut (Pheidole dan Tetramorium), lalat rumah (Muscadomestica) dan siput darat (Agriolimax sp.) (Levine, 1990; Kusumamihardja, 1990). Ayam buras di Desa Kramat dipelihara dengan kurang menjaga sanitasi kandang. Kandang yang digunakan adalah lahan kosong serta alas kandangnya merupakan tanah, serta ayam buras dipelihara dengan melepaskannya ke rawa-rawa pada waktu pagi hari sampai dengan sore hari untuk mencari makan sehingga memungkingkan ayam buras untuk memakan larva cacing atau cacing tanah dan menyebabkan ayam buras terinfeksi oleh cacing saluran pencernaan.

Telur cacing Heterakis gallinarum akan keluar bersama tinja dan mencapai tahap infektif (larva stadium kedua) dalam 12-14 hari pada suhu kamar. Jika telur infektif tertelan oleh ayam, maka akan menetas di dalam usus ayam dalam waktu 1-2 jam. Sebagian besar telur menetas di dalam empedu dan duodenum, kemudian larvanya akan bermigrasi menuju sekum untuk menjadi matang dalam waktu lebih 24 jam. Larva stadium kedua tinggal di dalam sekum selama 2-5 hari selanjutnya hari ke 4-6 setelah tertelan larva akan berkembang menjadi stadium ketiga dan menjadi dewasa sekitar 14 hari setelah tertelan. Masa prepaten cacing ini adalah 24-36 hari. Cacing tanah 
dapat menelan telur dan bertindak sebagai inang antara dan melindungi larva selama 1 tahun atau lebih (Kusumamiharja, 1990; Akoso, 1998). Ayam buras di Desa Kramat tiap pagi diberi pakan berupa dedak dan jagung agar kebutuhan karbohidrat ayam buras terpenuhi sehingga menghasilkan kualitas daging yang baik.

Cacing Nematoda yang menginfeksi ayam buras di Desa Kramat memiliki siklus hidup secara langsung yaitu dengan memakan telur cacing yang infektif. Selain itu telur Nematoda di alam akan lebih tahan terhadap temperatur tinggi dibandingkan dengan Cestoda dan Trematoda, karena memiliki lapisan albumin yang cukup tebal (Brotowidjojo, 1987). Cacing Tetrameres spp, merupakan salah satu cacing nematoda yang menyerang ayam buras. Infeki cacing tetrameres spp. yang ringan tidak akan menimbulkan perubahan klinis yang berarti, sedangkan infeksi yang berat pada ayam buras akan mengakibatkan anemia dan kekurusan (Baker, 2007).

Unggas terinfeksi cacing saluran pencernaan karena memakan inang antara yang terinfeksi oleh sistiserkoid cacing cestoda (Soulsby, 1986). Sistem pemeliharaan ayam buras di Desa Kramat tersebut kurang menjaga sanitasi kandang dan dibiarkan untuk mencari makan sendiri, kemungkinan ayam buras tidak sengaja memakan semut yang di dalam tubuh yang terdapat sistiserkoid cacing cestoda.

Berbeda dengan cacing Tetrameres sp, merupakan salah satu cacing nematoda yang menyerang ayam buras. Infeki cacing Tetrameres spp. yang ringan tidak akan menimbulkan perubahan klinis yang berarti, sedangkan infeksi yang berat pada ayam buras akan mengakibatkan anemia dan kekurusan (Baker, 2007).

\section{Kesimpulan}

Berdasarkan hasil penelitian, maka dapat diambil kesimpulan sebagai berikut, jenis cacing saluran pencernaan yang menginfeksi ayam buras di Desa Kramat yaitu Capillaria sp., Hymenolepissp., Railletina sp. dan Heterakis gallinarum. Prevalensi cacing saluran pencernaan pada ayam buras total di Desa Kramat dari jenis kelamin jantan 30\% dan betina $46 \%$. Rata-rata derajat infeksi cacing saluran pencernaan pada ayam buras di Desa Kramat dari jenis kelamin jantan sebesar $45 \cdot 53 \%$ dan $55.47 \%$.

\section{Daftar Pustaka}

Armour, J. 1980. The Epidemiology of Helminth Disease in Farm Animals. Vet. Parasitol. 6: 7-46.

Baker DG. 2007. Flynn's Parasites of Laboratory Animals. $2^{\text {nd }}$ Ed. American College of Laboratory Animal Medicine: Blackwell Publishing. P. 395-402.

Brotowidjoyo, M.D. 1987. Parasit dan Parasitisme, Edisi Pertama. Media Sarana Press, Jakarta. Hal 89 - 91.

Cynthia D, Kelly J, Fellers T and Michael W D. 2009. Trematode Flukes (Echinostoma Revolutum). Olympus MIC-D: Darkfield Gallery- Trematode Flukes (Echinostoma Revolutum). P. 256.

Fabiyi, J.P. 1986. Production Losses and Control of Helminths in Ruminants Tropical Regions. 111 Howells, M.L. (Ed.) Parasitology Quovadit/Proceecli,Igs of the Si.xttl ir tcrr atio rzl Cotzgress of Parasitology. Australian Academy of Science, Canberra.P. 435-442

Inbandiah, S. 1995. Kejadian infeksi cacing pita pada ayam buras di Kotabumi, Lampung Selatan.[Skripsi]. Fakultas Kedokteran Hewan Institut Pertanian Bogor.

Kusumamihardja, S. 1990. Parasit dan Parasitosis pada Hewan Ternak dan Hewan Piara di Indonesia.Pusat Antar UniversitasBioteknologi IPB, Bogor.

Lawson, J.L. and M.A. Gemmel. 1983. Transmission in Hydatidosis and Cysticercosis. Adl arice itı Para.sitology, 2a: 279 .

Levine N D. 1995. Buku Pelajaran Parasitologi Veteriner. Gatot Ashadi, penerjemah; Wardiarto, editor. Terjemahan dari: Textbook Veterinery Parasitology. Gadjah Mada University Press. Yogyakarta.354 363.

Levine, N.D. 1990. Buku Pelajaran Parasitologi Veteriner (terjemahan). Gadjah Mada University Press, Yogyakarta.76 - 77 .

Parede L, D Zainuddin dan H Huminto. 2005. Penyakit Menular pada Intensifikasi Unggas Lokal dan Cara Penanggulangannya. Lokakarya Nasional Inovasi Teknologi Pengembangan Ayam Lokal. Bogor. 86 hlm. 
Permin A and Hansen JW. 1998. FAO Animal Health Manual: Epidemiology, Diagnosis and Control of Poultry Parasites. Roma: FAO.Vol. 4: $226-233$

Pradana, P.P., T. Haryono, dan R. Ambarwati. 2015. Identifikasi Cacing Endoparasit pada Feses Ayam Pedaging dan Ayam Petelur. J.Lentera Bio. 4 (2):119-123.

Retnani EB. Satrija F, Hadi UK dan Sigit SH. 2009. Analisis Faktor-faktor Resiko Infeksi Cacing Pita pada Ayam Ras Petelur Komersial di Bogor. J. Vet; 10 (3): 165-172.

Roberts, M.G. 1994. Modeling of Parasitic Populations. Vet. Parasitol.(54): 145- 16o.

Shanin AM, Lebdah MA, Abu-Elkheir SA, Elmeligy MM. 2011. Prevalence of Chicken Cestodiasis in Egypt. New York Sci J; 4 (9): 21-29.

Siahaan, P.M. 1993. Identifikasi dan Pengaruh Cacing Parasit pada Saluran Pencernaan Ayam Buras di Kotamadya Medan dan sekitarnya. [Thesis]. Program Pacasarjana Institut Pertanian Bogor, 114 hlm.

Soulsby, E.J.L. 1986. Helminths, Arthropods, and Protozoa of Domesticated Animals. $7^{\text {th }}$ Ed. British Library Cataloguing in Publication Data. London. 55-56; 61; 99100; dan 162-165.
Sulistyati, M. , K. Hidayat, dan D. Garnida. 2001. Produktivitas Ayam Buras Hasil Seleksi Berdasarkan Pengetahuan Lokal Peternak. Jatinangor, Bandung 40600. $3(1): 46-53$.

Supranianondo, K., S. Romziah, S. N. Ddy, S. Hidanah, H.W. Sunaryo. 2011. Buku Ajar Manajemen Pemeliharaan Ternak Itik.Pusat Penerbitan dan Percetakan Universitas Airlangga. 12

Taylor, M.A., R.L. Coop, and R.L. Wall. 2007. Veterinary Parasitology. 3rd Ed. Blackwell Publishing. Australia. 460-462; 466-472 dan 493-500.

Yulianto, E. 2007. Hubungan Higiene Sanitasi dengan Kejadian Penyakit Cacingan pada Siswa Sekolah Dasar Negeri Rowosari o1 Kecamatan Tembalang Kota Semarang Tahun Ajaran 2006/2007 [Skripsi]. Fakultas Kesehatan Masyarakat. Universitas Negeri Semarang. 